\title{
Updated National and International Hypertension Guidelines: A Review of Current Recommendations
}

\author{
Sverre Kjeldsen • Ross D. Feldman • Liu Lisheng • \\ Jean-Jacques Mourad • Chern-En Chiang • \\ Weizhong Zhang $\cdot$ Zhaosu Wu $\cdot$ Wei Li $\cdot$ Bryan Williams
}

Published online: 15 October 2014

(C) The Author(s) 2014. This article is published with open access at Springerlink.com

\begin{abstract}
Despite the availability of effective pharmacological treatments to aid the control of blood pressure, the global rate of uncontrolled blood pressure remains high. As such, further measures are required to improve blood pressure control. Recently, several national and international guidelines for the management of hypertension have been published. These aim to provide easily accessible information for healthcare professionals and patients to aid the diagnosis and treatment of hypertension. In this review, we have compared new and current guidelines from the American and International Societies of Hypertension; the American Heart Association, American College of Cardiology and the US Center for Disease Control and Prevention; the panel appointed to the Eighth Joint National Committee; the European Societies of Hypertension and Cardiology; the French Society of Hypertension; the Canadian Hypertension Education Program; the National Institute for Health and Clinical Excellence (UK); the Taiwan Society of Cardiology and the Chinese Hypertension League. We have identified consensus opinion regarding best practises for the management of hypertension and have
\end{abstract}

S. Kjeldsen $(\square)$

Department of Cardiology, Faculty of Medicine,

Oslo University Hospital Ullevaal,

University of Oslo, 0450 Oslo, Norway

R. D. Feldman

Departments of Medicine and of Physiology and Pharmacology, Sculich School of Medicine and Dentistry, Western University, London, Canada

L. Lisheng · W. Li

Fu Wai Hospital, National Center for Cardiovascular Diseases, Beijing, China

J.-J. Mourad

Hypertension Excellence Centre-Avicenne University Hospital, AP-HP, Bobigny, France highlighted any discrepancies between the recommendations. In general there is good agreement between the guidelines, however, in some areas, such as target blood pressure ranges for the elderly, further trials are required to provide sufficient high-quality evidence to form the basis of recommendations.

\section{Key Points}

The recently published updates to European, American, Canadian, French, UK, Chinese and Taiwanese guidelines for hypertension broadly provide a consensus on the best practise for diagnosing and management of hypertension.

There are some areas, such as treatment goals for the elderly and for patients with diabetes, where there are discrepancies in the recommendations due to a lack of consistent and high-quality evidence to form the basis of recommendations.

\section{C.-E. Chiang \\ Division of Cardiology and General Clinical Research Center, Taipei Veterans General Hospital and National Yang-Ming University, Taipei, Taiwan}

W. Zhang

Shanghai Institute of Hypertension, Ruijin Hospital of Shanghai Jiaotong University, Shanghai, China

Z. Wu

An Zhen Hospital, Beijing, China

B. Williams

Institute of Cardiovascular Science, University College London, London, UK 


\section{Introduction}

The worldwide prevalence of hypertension is rising; the number of cases rose from 600 million in 1980 to 1 billion in 2008 [1]. Although hypertension itself is generally asymptomatic, it is one of the key risk factors for cardiovascular disease (CVD). Hypertension accounts for approximately $45 \%$ of deaths due to heart disease and $51 \%$ of deaths due to stroke [1]. Complications of hypertension are thought to cause 9.4 million deaths each year, and without further action the World Health Organization (WHO) has predicted this number will increase [1]. It has been predicted that by 2030 nearly a quarter of all deaths worldwide will be due to CVD [1]. However, if hypertension was controlled in all patients, a substantial decrease in $\mathrm{CV}$ events would be seen; for example, in the UK it has been predicted that the incidence of stroke would be reduced by $28-44 \%$ and ischaemic heart disease by 20-35\% [2].

Effective treatments to control blood pressure (BP) are available but measures need to be taken to ensure their use is maximised in the required patient groups. To achieve this, effective multifactorial programmes with strategies to manage blood pressure are being sought. As part of this programme, clear evidence-based guidelines that can be readily implemented across diverse populations are required. Indeed, clinical guidelines are considered the intersection between evidence and clinical practice to improve patients' CV outcomes [3].

In 2013, a number of national and international hypertension guidelines were updated. Although these guidelines have evolved to reflect new evidence and best practice, the objective remains unequivocal: to develop recommendations, based on clinical evidence, to aid the diagnosis, treatment and management of hypertension. In light of the recent updates, we felt it important to review and compare the latest updates with currently utilised regional guidelines. The review will discuss hypertension guidelines from the US including those from the Eighth Joint National Committee (JNC 8) (updated 2013) [3-5], regularly updated Canadian recommendations (annual non-radical updates) [6], European (European Societies of Hypertension and Cardiology (ESH/ESC]) guidelines (updated in 2013) [7], UK (National Institute for Health and Clinical Excellence [NICE); last updated in 2011) [8], France (updated in 2013) [9], Taiwan (last updated in 2010 [pending update in 2014]) [10] and China (last updated in 2010) [11]. Table 1 [3-11] provides an overview of the development and aims of these guidelines.

All the guidelines were produced by committees of healthcare professionals and scientists with a broad range of expertise in the field of hypertension and principally used evidence from systematic reviews of randomised control trials (RCT) [3-11]. Notably, NICE also has patients on the panel to support the development and updating of their clinical practice guidelines [8]. The guidelines were developed as a means of improving and standardising the management of hypertension within their jurisdictions. It is important to note that all the guidelines state that they are not mandatory, but aim to help facilitate the physicians' treatment decisions on a case by case basis.

By comparing these guidelines, we aim to identify the major differences in recommendations and establish where there is consensus on best practice for hypertension management (summarised in Table 2). Specifically, the review will focus on recommendations for the utilisation of diagnostic tools, the BP levels defined for initiating treatment, target BP levels, and the proposed non-pharmacological and pharmacological interventions. Further to this analysis, we will collectively provide our expert opinion on the future development of guidelines and how best to implement these into clinical practice.

\section{Tools for Diagnosing Hypertension and Monitoring Blood Pressure}

Accurate diagnosis of hypertension and the identification of other CV risk factors is essential to identify patients that will likely benefit from treatment to control BP [1]. Based on office BP measurements, all the guidelines utilise a common definition of stage 1 hypertension as clinic seated systolic (SBP)/diastolic (DBP) $\geq 140 / 90 \mathrm{mmHg}$ and stage 2 hypertension as $\geq 160 / 100 \mathrm{mmHg}$ [3-11]. Where stated, the guidelines are in agreement regarding the use of lower BP measurements for defining hypertension based on ambulatory (ABPM) or home blood pressure monitoring (HBPM). With the exception of the American Heart Association (AHA), American College of Cardiology (ACC), the Center for Disease Control and Prevention (CDC) and JNC 8 guidelines, all the guidelines discuss methods for diagnosing and monitoring BP $[3,4]$. With the exception of the NICE and Canadian Hypertension Education Program (CHEP) guidelines, the consensus is that a diagnosis of hypertension should be based on multiple office BP measurements, taken on at least two separate visits, 1-4 weeks apart [5, 7, 9-11]. The CHEP guidelines are more stringent and suggest that if SBP is $140-160 \mathrm{mmHg}$ or DBP 90-100 $\mathrm{mmHg}$, then office BP should be measured on four to five separate occasions, or self-monitoring/ABPM should be used before diagnosis is made [6].

Although the use of both ABPM and HBPM are recognised as effective diagnostic tools that are becoming more widely used, only the CHEP and NICE guidelines currently recommend that a diagnosis can be made based on either of these measurements $[6,8]$; for all other 


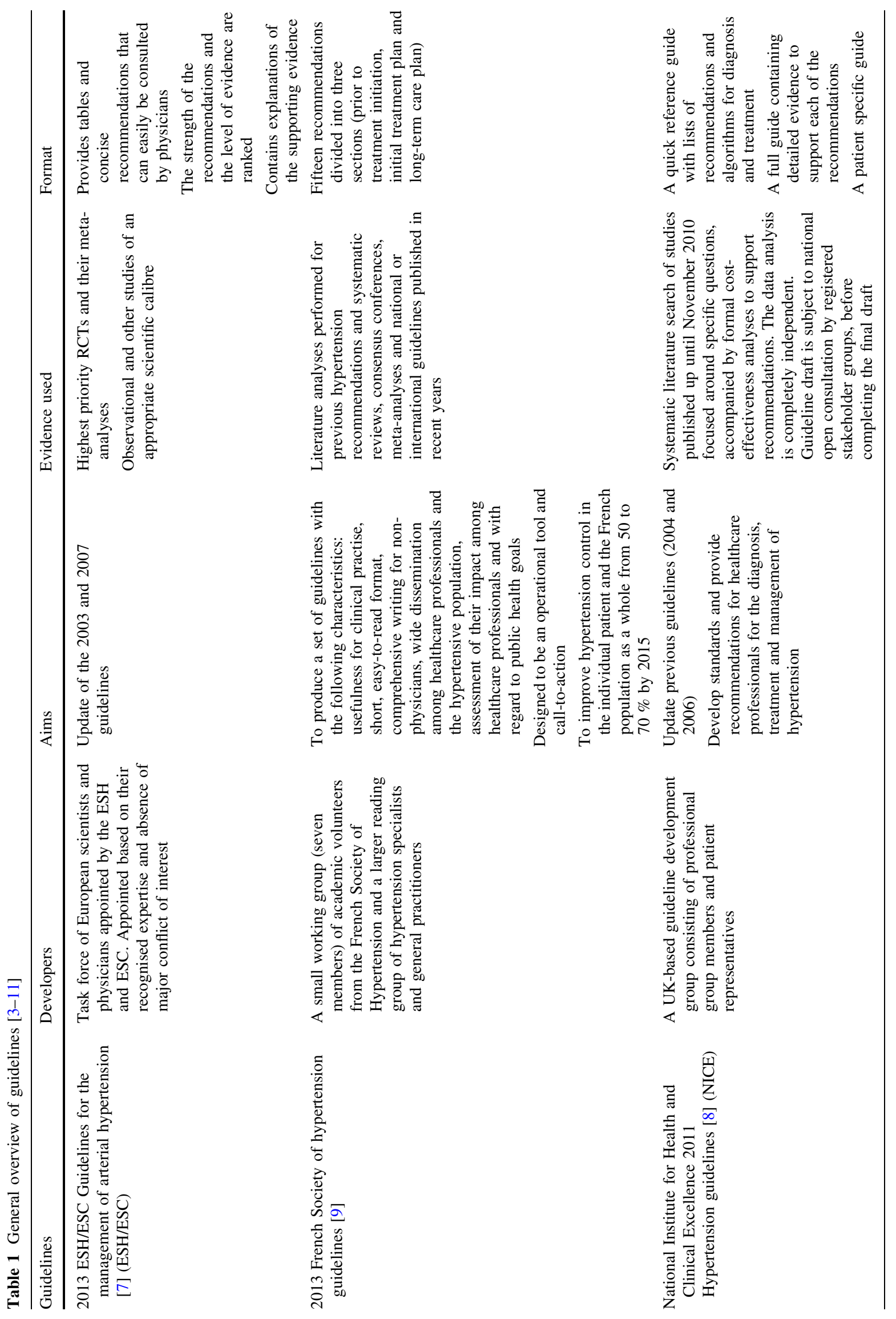




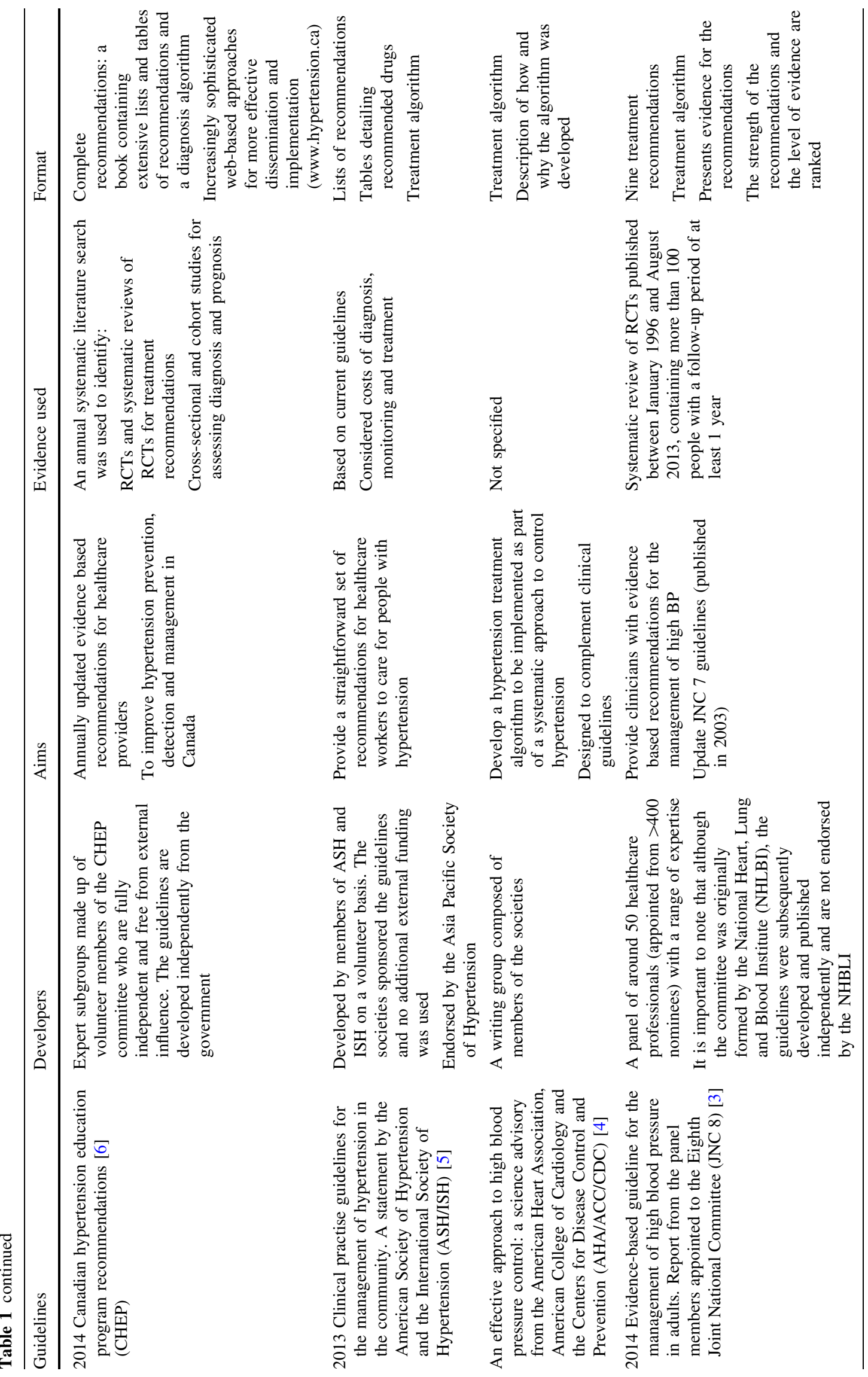




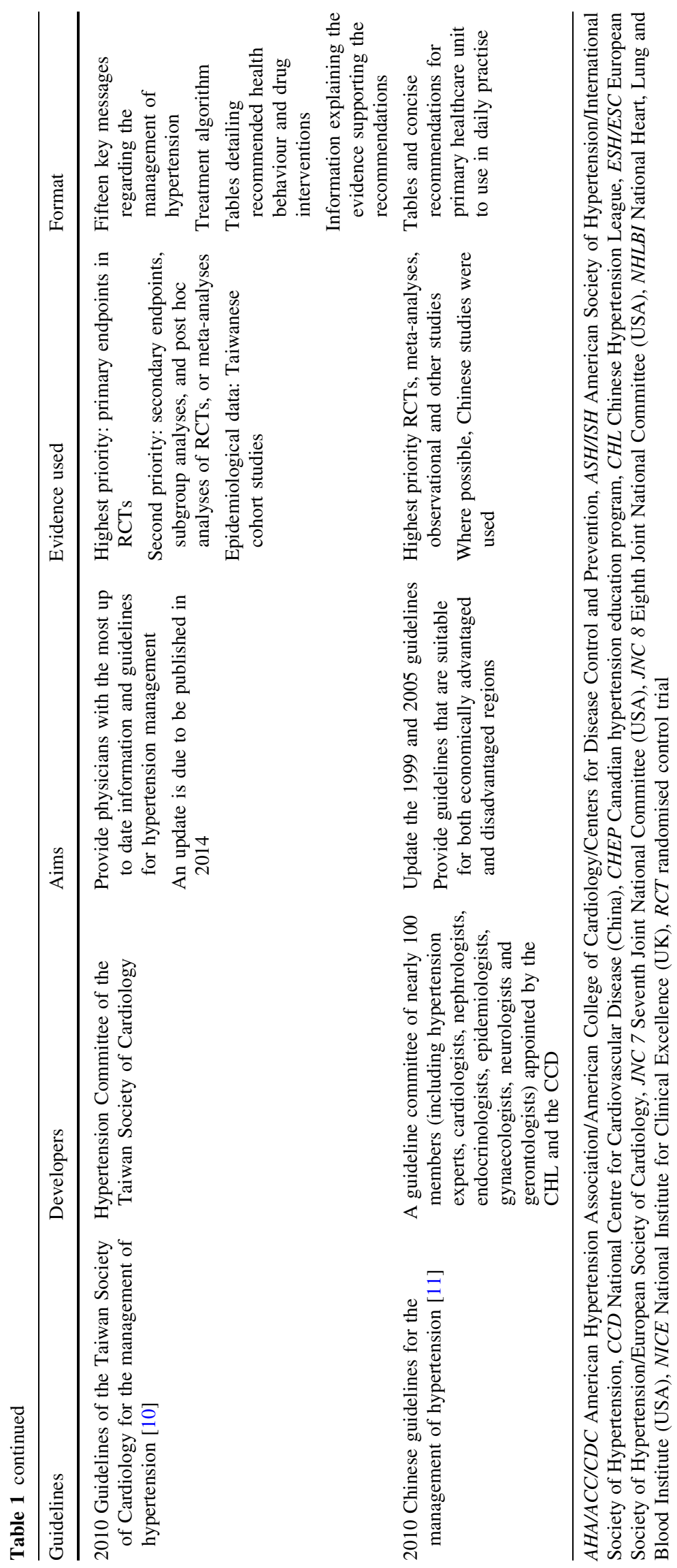


Table 2 Summary highlighting the major consensus findings and discrepancies between guidelines

\begin{tabular}{|c|c|c|}
\hline & Consensus opinion $^{a}$ & Discrepancies \\
\hline Measuring BP & $\begin{array}{l}\text { Multiple office BP measurements are the gold } \\
\text { standard for diagnosis } \\
\text { Self-monitoring can aid diagnosis and long-term BP } \\
\text { monitoring }\end{array}$ & $\begin{array}{l}\text { NICE states that ABPM is the gold standard for diagnosis } \\
\text { before initiating therapy-daytime average BP }>135 / 85 \\
\text { defined as hypertension }\end{array}$ \\
\hline Target office BP & $<140 / 90 \mathrm{mmHg}$ for general population & $\begin{array}{l}\text { Differing targets for elderly } \\
\text { CHEP, Taiwan and EHC/ESC recommend lower target for } \\
\text { patients with diabetes or CKD }\end{array}$ \\
\hline $\begin{array}{l}\text { Health behaviour } \\
\text { modifications }\end{array}$ & $\begin{array}{l}\text { Important role in combination with pharmacological } \\
\text { treatment } \\
\text { Focus on the same factors e.g., diet and exercise }\end{array}$ & $\begin{array}{l}\text { Initiation before (ASH/ISH, AHA/ACC/CDC, ESH/ESC, } \\
\text { NICE, France) or in conjunction (China, Taiwan), with } \\
\text { pharmacological treatment }\end{array}$ \\
\hline $\begin{array}{l}\text { Pharmacological } \\
\text { treatment }\end{array}$ & $\begin{array}{l}\text { Individualise treatment to meet patient needs } \\
\text { Principally use } 4 \text { classes of drugs, diuretics, CCB, } \\
\text { ACEI and ARB } \\
\text { Simplify drug regimens by using long-acting drugs } \\
\text { and SPCs } \\
\text { Gaining BP control as soon as possible improves } \\
\text { persistence } \\
\text { Patient education improves persistence } \\
\text { Regular monitoring is required }\end{array}$ & $\begin{array}{l}\beta \text {-Blockers are not advised for treatment of general population } \\
\text { in the JNC } 8, \mathrm{ASH} / \mathrm{ISH} \text {. AHA/ACC/CDC, NICE, Taiwan } \\
\text { guidelines and are restricted to those }<60 \text { years of age in } \\
\text { CHEP guidelines }\end{array}$ \\
\hline Drug combinations & $\begin{array}{l}\text { Multiple drugs are required in most cases } \\
\text { SPCs can be used when available } \\
\text { ACEI and ARB should not be used in combination } \\
\text { CCB + thiazide + ACEI/ARB is the preferred } \\
\text { 3-drug combination }\end{array}$ & $\begin{array}{l}\text { SPCs recommended by China and Taiwan guidelines for initial } \\
\text { treatment if more than one drug is required } \\
\text { No consensus on drug class to be used for initial treatment } \\
\text { No consensus on most effective 2-drug combinations }\end{array}$ \\
\hline $\begin{array}{l}\text { Treatment } \\
\text { recommendations for } \\
\text { specific patient groups }\end{array}$ & $\begin{array}{l}\text { Specific treatment recommendations are required } \\
\text { for patients with associated comorbidities } \\
\text { Treatment of black patients should be initiated with } \\
\text { CCB or thiazide diuretic } \\
\beta \text {-Blockers should be prescribed for patients with a } \\
\text { history of myocardial infarction, heart failure or } \\
\text { angina pectoris }\end{array}$ & - \\
\hline Treatment algorithms & $\begin{array}{l}\text { A useful tool for providing simplified treatment } \\
\text { advice }\end{array}$ & - \\
\hline
\end{tabular}

AHA/ACC/CDC American Hypertension Association/American College of Cardiology/Centers for Disease Control and Prevention, ASH/ISH American Society of Hypertension/International Society of Hypertension, CHEP Canadian hypertension education program, ESH/ESC European Society of Hypertension/European Society of Cardiology, JNC 8 Eighth Joint National Committee, NICE National Institute for Clinical Excellence (UK), $A B P M$ ambulatory blood pressure monitoring, $A C E I$ angiotensin converting enzyme inhibitor, $A R B$ angiotensin receptor blocker, $B P$ blood pressure, $C C B$ calcium channel blocker, $C K D$ chronic kidney disease, SPC single pill combination

${ }^{a}$ Consensus recommendations are those that are presented in the majority of the guidelines, with no conflicting advice presented in the other guidelines (although the subject may not be discussed)

guidelines office BP is still regarded as the gold standard for diagnosis [3-5, 7, 9-11]. Uniquely, the NICE guidelines recommend that office BP is used to initially screen for hypertension, with ABPM (or HBPM if patients are unable or unwilling to use ABPM) then used to confirm the diagnosis [8]. French and Taiwan guidelines recommend the use of self-monitoring to confirm office BP measurements before diagnosis is made [9, 10], while other guidelines (American and International Societies of Hypertension [ASH/ISH] and ESH/ESC) recommend selfmonitoring for borderline cases, when variable office BP measurements are recorded or when white-coat hypertension is suspected [5, 7]. The ESH/ESC and NICE guidelines state that ABPM is the preferred method of selfmonitoring for diagnosis [7, 8], although French and ESH/ ESC guidelines state that HBPM is more suitable than ABPM for monitoring BP subsequent to diagnosis [7, 9]. In Taiwan and Canada, the cost of ABPM is not reimbursed by the National Health Insurance System, therefore its use is limited and HBPM is more widely used [10]; this is an example of how healthcare resource and financial constraints can enforce differences in recommendations. As the cost of ABPM decreases its use is likely to become more commonplace. Indeed, a UK-based study 
investigating the cost effectiveness of using $A B P M$ for diagnosis concluded that the additional cost of implementing ABPM outweighed the savings made by providing more accurate diagnosis and treatment [12].

\section{Blood Pressure Thresholds for Initiating Treatment}

There is some disparity between the guidelines regarding when drug treatment to control BP should be initiated (Table 3 [3-11]). The Taiwan guidelines are the only guidelines to recommend treatment of patients with high-normal BP $(130-139 / 80-89 \mathrm{mmHg})$ if they have additional risk factors [10]. Both the French and Taiwan guidelines recommend commencing pharmacological treatment of stage 1 patients regardless of other risk factors, whereas the other guidelines recommend a trial period of health behaviour modifications to try and control BP without therapy. The recommended duration of this period varies from several months in the ESH/ESC guidelines [7], 3 months in the AHA/ ACC/CDC guidelines [4], to 6-12 months in the ASH/ISH guidelines [5] (NICE guidelines do not specify a time period [8]). In addition, the French guidelines recommend health behaviour modifications commence prior to a confirmed diagnosis of hypertension [9]. The NICE and Canadian recommendations note that for those at very low risk (the paradigm being a pre-menopausal female with no other risk factors, or younger people) with an SBP of $<160 \mathrm{mmHg}$ and DBP $<100 \mathrm{mmHg}$, initiation of antihypertensive therapy can be deferred. This recommendation is in accordance with their very low risk for $\mathrm{CV}$ complications, subsequent low probability of benefiting from therapy and that lack of evidence for treatment in low-risk patients with stage 1 hypertension [6, 8].

With the exception of the ESH/ESC guidelines, all guidelines recommend commencing pharmacological treatment of stage 2 patients immediately following diagnosis. The ESH/ESC recommend that, even low-risk stage 2 patients undergo a phase of health modifications before commencing treatment.

Some guidelines provide specific recommendations for initiating treatment of the elderly. ESH/ESC, NICE and CHEP suggest that for patients aged $\geq 80$ years, an SBP of $>160 \mathrm{mmHg}$ should be used as a threshold for initiating pharmacological intervention [6-8]. JNC 8 guidelines recommend initiating treatment of patients aged $\geq 60$ years if their $\mathrm{BP}$ is $\geq 150 / 90 \mathrm{mmHg}$ [3].

\section{Target Blood Pressure Levels}

\subsection{Elderly Patients}

All the guidelines have the same target of SBP $\leq 140$ and DBP $\leq 90 \mathrm{mmHg}$ for the general adult population, however, some variations exist in the recommendations for specific groups of patients (Table 4 [3-11]). The AHA/ ACC/CDC and Taiwan guidelines do not contain any specific BP targets for the elderly, whereas the JNC 8, ESH/ESC, ASH/ISH, French, NICE, CHEP and China guidelines suggest that a higher target of $<150 / 90 \mathrm{mmHg}$ is appropriate based largely on data from the HYVET study [13]. It is important to note, however, that the definition of elderly varies between the guidelines: JNC 8 guidelines class elderly as $\geq 60$ years of age [3], China as $\geq 65$ years of age [11], and the ASH/ISH, French, NICE, CHEP and ESH/ESC guidelines define it as people $\geq 80$ years $[5,7-$ 9]. The ESH/ESC guidelines make this recommendation with the additional caveat that if the patient is otherwise considered healthy then a target SBP $\leq 140 \mathrm{mmHg}$ is recommended [7]. It has been reported that the higher target BP $(<150 / 90 \mathrm{mmHg})$ for the elderly population (defined as $\geq 60$ years of age), recommended by the JNC 8 guidelines, was one of the few recommendations where the committee failed to reach consensus [14]. The majority of the JNC 8 panel concluded that, as there was no definitive evidence to determine target BP levels in the elderly, increasing the target SBP from 140 to $150 \mathrm{mmHg}$ was the optimum approach [14]. However, a minority group indicated that CVD prevalence in the USA could rise should this less stringent target be implemented in clinical practice. The minority group insisted the higher BP target to be recommended only for those over 80 years of age, in alignment with the majority of national guidelines [14].

\subsection{Patients with Diabetes or Chronic Kidney Disease}

The recommended target BP for patients with comorbidities has evolved and become less stringent across the guidelines due to a lack of quality evidence. Although some guidelines (e.g., ESH/ESC 2007 and JNC 7 guidelines $[15,16]$ ) have previously advised a lower target BP $(\leq 130 / 80 \mathrm{mmHg})$ in patients with chronic kidney disease (CKD) or diabetes, the majority of guidelines now state that there is not sufficient evidence to support this recommendation and have deferred back to a more conservative evidence-based treatment goal for the general population $(\leq 140 / 90 \mathrm{mmHg})$. For example, in the case of patients with diabetes, both the ESH/ESC and JNC 8 guidelines cite the action to control cardiovascular risk in diabetes (ACCORD) trial which showed no additional benefit of lowering $\mathrm{SBP}<130 \mathrm{mmHg}$ (although the study was under powered) [17]. However, based on results of the hypertension optimal treatment (HOT) [18] and United Kingdom Prospective Diabetes Study (UKPDS) [19] the ESH/ESC guidelines suggest a lower target DBP $(<85 \mathrm{mmHg})$ [7]. In contrast, the JNC 8 panel concluded that based on 
Table 3 Blood pressure thresholds for initiating treatment ${ }^{\mathrm{a}}[3-11]$

\begin{tabular}{|c|c|c|c|c|c|c|c|c|c|}
\hline $\begin{array}{l}\text { Patient } \\
\text { group }\end{array}$ & Recommendation & ASH/ISH & $\begin{array}{l}\text { AHA/ACC/ } \\
\text { CDC }\end{array}$ & ESH/ESC & NICE & France & Taiwan & CHEP & China \\
\hline $\begin{array}{l}\text { High } \\
\text { normal } \\
\text { BP, high } \\
\text { risk }\end{array}$ & $\begin{array}{l}\text { Health behaviour } \\
\text { modifications } \\
\text { and } \\
\text { pharmacological } \\
\text { treatment }\end{array}$ & & & & & & $\checkmark$ & & \\
\hline \multirow[t]{2}{*}{$\begin{array}{l}\text { Stage } 1 \text {, low } \\
\text { risk }\end{array}$} & $\begin{array}{l}\text { Health behaviour } \\
\text { modifications } \\
\text { and monitoring } \\
\text { before initiating } \\
\text { pharmacological } \\
\text { treatment }\end{array}$ & $\checkmark$ & $\checkmark$ & $\checkmark$ & $\checkmark$ & & & & \\
\hline & $\begin{array}{l}\text { Health behaviour } \\
\text { modifications } \\
\text { and } \\
\text { pharmacological } \\
\text { treatment }\end{array}$ & & & & & $\checkmark$ & $\checkmark$ & & $\checkmark$ \\
\hline $\begin{array}{l}\text { Stage 1, } \\
\text { high risk }\end{array}$ & $\begin{array}{l}\text { Health behaviour } \\
\text { modifications } \\
\text { and } \\
\text { pharmacological } \\
\text { treatment }\end{array}$ & $\checkmark$ & $\checkmark$ & $\checkmark$ & $\checkmark$ & $\checkmark$ & $\checkmark$ & $\checkmark$ & $\checkmark$ \\
\hline \multirow[t]{2}{*}{$\begin{array}{l}\text { Stage 2, low } \\
\text { risk }\end{array}$} & $\begin{array}{l}\text { Health behaviour } \\
\text { modifications } \\
\text { and monitoring } \\
\text { before initiating } \\
\text { pharmacological } \\
\text { treatment }\end{array}$ & & & $\checkmark$ & & & & & \\
\hline & $\begin{array}{l}\text { Health behaviour } \\
\text { modifications } \\
\text { and } \\
\text { pharmacological } \\
\text { treatment }\end{array}$ & $\checkmark$ & $\checkmark$ & & $\checkmark$ & $\checkmark$ & $\checkmark$ & $\checkmark$ & $\checkmark$ \\
\hline $\begin{array}{l}\text { Stage 2, } \\
\text { high risk }\end{array}$ & $\begin{array}{l}\text { Health behaviour } \\
\text { modifications } \\
\text { and } \\
\text { pharmacological } \\
\text { treatment }\end{array}$ & $\checkmark$ & $\checkmark$ & $\checkmark$ & $\checkmark$ & $\checkmark$ & $\checkmark$ & $\checkmark$ & $\checkmark$ \\
\hline $\begin{array}{l}\text { Elderly, } \\
>80 \text { years }\end{array}$ & $\begin{array}{l}\text { Health behaviour } \\
\text { modifications } \\
\text { and } \\
\text { pharmacological } \\
\text { treatment }\end{array}$ & $\begin{array}{l}\text { Not } \\
\text { specified }\end{array}$ & $\begin{array}{l}\text { Not } \\
\text { specified }\end{array}$ & $\begin{array}{l}\boldsymbol{V}(\mathrm{SBP} \\
\geq 160 \mathrm{mmHg} \\
\text { only) }\end{array}$ & $\begin{array}{l}\text { Not } \\
\text { specified }\end{array}$ & $\checkmark$ & $\begin{array}{l}\text { Not } \\
\text { specified }\end{array}$ & $\begin{array}{l}\boldsymbol{V} \text { (SBP } \\
\geq 160 \mathrm{mmHg} \\
\text { only) }\end{array}$ & $\begin{array}{l}\text { Not } \\
\text { specified }\end{array}$ \\
\hline
\end{tabular}

AHA/ACC/CDC American Hypertension Association/American College of Cardiology/Centers for Disease Control and Prevention, ASH/ISH American Society of Hypertension/International Society of Hypertension, CHEP Canadian hypertension education program, ESH/ESC European Society of Hypertension/European Society of Cardiology, JNC 8 Eighth Joint National Committee, NICE National Institute for Clinical Excellence (UK), $S B P$ systolic blood pressure

${ }^{a}$ Note that this subject is not discussed in JNC 8 guidelines

these trials there were not sufficient good quality data to recommend a lower target DBP. This discrepancy may at least in part be due to the JNC 8 panel focusing on the effect on mortality whereas ESH/ESC analysed data regarding all $\mathrm{CV}$ events and used post hoc analysis (which was disregarded by the JNC 8 committee) of patient subgroups from the HOT trial.
The CHEP and Taiwan guidelines recommend patients with diabetes should be treated to attain BP of $\leq 130$ / $80 \mathrm{mmHg}[6,10]$. This recommendation is based on results from the HOT study and several recent meta-analyses that have shown that achieving a lower BP reduces the risk of stroke without resulting in an increase in myocardial infarction [18, 20-22]. 
Table 4 Blood pressure target levels cited by each guideline across general and special populations [3-11]

\begin{tabular}{lll}
\hline Population & $\begin{array}{l}\text { Target BP } \\
\text { (SBP/DBP } \\
\text { mmHg) }\end{array}$ & \\
\hline General & $<140 / 90$ & All $^{\mathrm{a}}$ \\
Elderly & & \\
$\geq 60$ years & $<150 / 90$ & JNC 8 \\
$\geq 65$ years & $<150 / 90$ & China \\
$\geq 80$ years & $<150 / 90$ & ASH/ISH, ESH/ESC, \\
& & France, NICE, CHEP \\
Diabetes & $<130 / 80$ & CHEP, China, Taiwan \\
& $<140 / 85$ & ESH/ESC \\
CKD & $<130 / 80$ & China, Taiwan, ESH/ESC \\
Other high-risk patients & $<130 / 80$ & Taiwan, China \\
e.g., with coronary & & \\
disease, history of stroke & & \\
\hline
\end{tabular}

AHA/ACC/CDC American Hypertension Association/American College of Cardiology/Centers for Disease Control and Prevention, ASH/ ISH American Society of Hypertension/International Society of Hypertension, CHEP Canadian hypertension education program, ESH/ESC European Society of Hypertension/European Society of Cardiology, JNC 8 Eighth Joint National Committee, NICE National Institute for Clinical Excellence (UK), $C K D$ chronic kidney disease, $D B P$ diastolic blood pressure, SBP systolic blood pressure

a The French guidelines suggest a target range of $130-139 \mathrm{mmHg}$ for SBP

${ }^{\mathrm{b}}$ In patients with proteinuria

${ }^{c}$ For CHD patients only

In the case of CKD, only the China, Taiwan and ESH/ ESC (with proteinuria) guidelines recommend a lower target $\mathrm{BP}(\leq 130 / 80 \mathrm{mmHg})$ [7, 10, 11]. The ESH/ESC guidelines highlight the lack of clear evidence to support this target, with recent meta-analyses failing to demonstrate any benefit from achieving lower BP [23, 24]; however, there is some limited evidence that suggests a lower target may be beneficial in patients with proteinuria $[7,25]$.

\section{Health Behaviour Intervention Strategies}

All guidelines recommend that health behaviour changes form part of the treatment of hypertension (Table 5 [3-11, 26]). Although the AHA/ACC/CDC, ESH/ESC, ASH/ISH and NICE guidelines recommend a period of health behaviour modifications prior to initiating pharmacological treatment, in general, health behaviour modifications should be seen as complementary to drug therapy and not an alternative $[4,5,7,8]$.

The health behaviour modifications are generally similar between guidelines, with a focus on a diet rich in fruit and vegetables and low in saturated fat, regular physical exercise, weight loss, reduced alcohol and sodium consumption, and smoking cessation. The main inconsistency is the China guidelines recommend increasing potassium intake (as the typical Chinese diet is low in potassium) [11], whereas CHEP and NICE guidelines specifically state that potassium supplementation is not recommended as there is not sufficient evidence to demonstrate any benefit $[6,8]$.

Although all guidelines recommend lowering salt intake, the suggested levels vary. Currently, the average per-person salt intake is 9-12 g/day and WHO recommends reducing this to $<5 \mathrm{~g}$ salt $(2,000 \mathrm{mg}$ sodium) per day [1]; the ESH/ESC, NICE, AHA/ACC/CDC, JNC 8, CHEP, China and Taiwan guidelines all suggest a similar target $[3,4,7,8,10,11]$. Although the ASH/ISH and French guidelines suggest reducing salt intake, they do not suggest a target level [5, 9]. Inconsistencies in salt intake recommendations may be due to conflicting evidence surrounding the optimal level of dietary salt. Although high levels of salt have been linked with hypertension and an increased risk of CVD, some reports suggest low salt intake may be associated with higher cardiovascular mortality and adverse health outcomes (primarily in non-hypertensive patient populations and those with significant cardiovascular co-morbidities) [27-29].

\section{Pharmacological Treatment Recommendations}

All guidelines recommend four main drug classes for the treatment of hypertension: angiotensin-converting enzyme inhibitors (ACEI), angiotensin receptor blockers (ARB), calcium channel blockers (CCB) and diuretics. As the main benefits of antihypertensive treatments are due to the lowering of BP per se and are independent of the specific drugs utilised, it is accepted that there is no need to differentiate between drugs within each class [7]. The advice regarding the use of $\beta$-blockers for the general hypertensive population is variable; the ESH/ESC, French and China guidelines recommend their use [7, 9, 11]; the JNC 8, NICE and ASH/ISH guidelines recommend them as an additional drug if $\mathrm{BP}$ cannot be controlled with the other drug classes [3, 5, 8]; Taiwan and AHA/ACC/CDC guidelines only recommend their use in specific patient groups (as discussed below) [4, 10]. In addition, based on the findings of the Medical Research Council (MRC) study of antihypertensives for the elderly, where $\beta$-blockers were found to be less effective at preventing CV events compared with diuretics [30], CHEP recommends they are only used in the initial treatment of those under 60 years of age [6]. These discrepancies in the recommended use of $\beta$ blockers are due to evidence from some trials suggesting that they are less effective than other drug classes at 
Table 5 Non-pharmacological interventional strategies by guideline [3-11, 26]

Guidelines What is recommended?

JNC 8

ASH/ISH

AHA/ACC/CDC

CHEP

$\mathrm{ESH} / \mathrm{ESC}$

France

NICE
Not specifically addressed, but supports the recommendations of the 2013 Lifestyle Work Group, a set of diet and activity guidelines to reduce $\mathrm{CV}$ disease risk [26]

Weight loss in patients who are overweight or obese

Reduce salt intake

Regular exercise as part of the daily routine

Reduce alcohol consumption-Up to 2 drinks a day for men and 1 for women

Stopping smoking

Maintain BMI $18.5-24.9 \mathrm{~kg} / \mathrm{m}^{2}$

Consume a diet rich in fruits, vegetables and low-fat dairy products with a reduced content of saturated and total fat

Consume no more than 2,400 mg sodium/day. Further reduction of sodium intake to $1,500 \mathrm{mg} /$ day is desirable since it is associated with even greater reduction in BP. Reduce intake by at least $1,000 \mathrm{mg} /$ day since that will lower BP, even if the desired daily sodium intake is not achieved

Engage in regular aerobic physical activity such as brisk walking at least 30 min per day, most days of the week

Limit alcohol consumption to no more than 2 drinks per day in most men, and no more than 1 drink per day in women and lighter weight persons

Physical exercise: 30-60 min moderate intensity dynamic exercise 4-7 days a week

Weight reduction: target BMI $18.5-24.9 \mathrm{~kg} / \mathrm{m}^{2}$ and waist circumference $<102 \mathrm{~cm}$ for men and $<88 \mathrm{~cm}$ for women

Alcohol consumption: two drinks or less per day, with consumption not exceeding 14 or 9 standard drinks per week for men and women, respectively (standard drink is considered $17.2 \mathrm{ml}$ ethanol)

Diet: consume a diet that emphasises fruits, vegetables, low-fat dairy products, dietary and soluble fibre, whole grains and protein from plant sources that is reduced in saturated fat and cholesterol

Reduce sodium intake towards $5 \mathrm{~g}$ of salt daily

Supplementation of potassium, calcium and magnesium is not recommended

Stress management

Salt reduction

Moderation of alcohol consumption, no more than 20-30 g ethanol per day in men and 10-20 g in women

Consume a diet of vegetables, fruits and low-fat dairy products, dietary and soluble fibre, whole grains and proteins from plant sources

Reduce consumption of saturated fat and cholesterol

Weight reduction for overweight or obese patients

Regular physical exercise, 30-60 min moderate intensity dynamic exercise 5-7 days a week

Cessation of smoking

Reduce excessive salt consumption

Regular physical activity

Reduce weight if overweight

Reduce excessive consumption of alcohol

Adopt a diet rich in fruit and vegetables

Cease smoking

Provide diet and exercise advice

Reduce alcohol consumption

Reduce consumption of coffee and caffeine-rich products

Reduce salt intake

Cease smoking

Calcium, magnesium and potassium supplements are not recommended

Relaxation therapies 
Table 5 continued

\begin{tabular}{ll}
\hline Guidelines & What is recommended? \\
\hline Taiwan & S-ABCDE: \\
& Salt restriction \\
& Alcohol limitation \\
& Body weight reduction \\
& Cessation of smoking \\
& Diet adaption \\
& Exercise adoption \\
& Sodium reduction \\
& Smoking cessation \\
Rhina & Reduction of body weight \\
& Reduction in alcohol consumption \\
& Increase dietary potassium \\
& Increase physical activity \\
\hline
\end{tabular}

AHA/ACC/CDC American Hypertension Association/American College of Cardiology/Centers for Disease Control and Prevention, ASH/ISH American Society of Hypertension/International Society of Hypertension, CHEP Canadian hypertension education program, ESH/ESC European Society of Hypertension/European Society of Cardiology, JNC 8 Eighth Joint National Committee, NICE National Institute for Clinical Excellence (UK), $B M I$ body mass index, $B P$ blood pressure, $C V$ cardiovascular

controlling BP, not as effective in preventing stroke or other CV events [31], and due to many of the drugs being associated with adverse effects such as reduced sexual function, fatigue, reduced exercise tolerance, increase in body weight and increased incidence of new onset diabetes $[5,7,10]$.

The guidelines principally base their recommendations on classes of drugs and do not make intraclass differences between antihypertensives. Notably, the NICE recommendations preferentially recommend indapamide and chlorthalidone ahead of thiazide diuretics [8]. This approach has been questioned in the ESH reappraisal of their recommendations [7]. In regards to $\beta$-blockers none of the guidelines deal with the issue of whether there are significant intraclass differences between $\beta$-blockers, for example, whether newer $\beta$-blockers like nebivolol or carvedilol may be superior to older generation drug [32-34].

Other less frequently recommended classes of drugs, which are generally only recommended for specific patient groups, include $\alpha$-blockers, direct vasodilators, mineralocorticoid receptor antagonist and $\alpha-2$ agonists. The use of direct vasodilators such as hydralazine and minoxidil is only discussed in the ASH/ISH guidelines, which suggests they should only be considered as a fourth-line or later addition to the treatment regimen as they often cause adverse effects, such as fluid retention and tachycardia [5].

The guidelines are all in agreement that patient adherence is critical to achieving BP control. To aid this, it is important that the simplest treatment regimen is utilised to establish and maintain persistence. As such, longer-acting drugs that only require once-daily dosing are preferred [311]. Patient education is also a recognised factor in achieving a high level of persistence; the French guidelines reinforce this by recommending patients have a consultation dedicated to providing disease and treatment information prior to commencing drug treatment [9]. Personalised treatment regimens are required to enhance adherence; therefore, to meet the individual's needs it is important to account for issues regarding tolerability and efficacy when deciding on the optimum treatment regimen. To aid this, the guidelines provide flexible treatment regimens for the general hypertensive population and specific guidelines influenced by the age, ethnicity and other clinical characteristics of the patient (e.g., diabetes, coronary disease, etc.) associated with hypertension.

All guidelines under review recognise that reaching BP control as soon as possible is essential for gaining patient confidence in the treatment and improving adherence. The majority of guidelines under review do not specify a timeframe for achieving BP control $[3,4,6-8,10,11]$; however, the ASH/ISH guidelines state that an effective treatment regimen should be established within 6-8 weeks of initiating treatment [5], while the French guidelines recommend that an appropriate treatment regimen be established within 6 months of initiating treatment [9]. Once an effective treatment regimen is established, the guidelines all recommend self-monitoring of $\mathrm{BP}$ to be used in combination with regular clinical visits to maintain patient persistence with drug and health behaviour changes, and to enable monitoring of treatment efficacy and adverse effects [3-11]. 
Table 6 Treatment algorithms [3-11]

\begin{tabular}{|c|c|c|}
\hline Guidelines & Patient characteristics & Treatment recommendations \\
\hline JNC 8 & $\begin{array}{l}\text { Patients categorised based on age, goal BP, race } \\
\text { and patients with diabetes/CKD }\end{array}$ & $\begin{array}{l}\text { Specifies drug classes to be used as first-line treatment and longer-term } \\
\text { follow-up treatment options if BP remains uncontrolled }\end{array}$ \\
\hline ASH/ISH & $\begin{array}{l}\text { Patients categorised based on } \mathrm{BP} \text { and other factors } \\
\text { e.g., age, race, comorbidities }\end{array}$ & $\begin{array}{l}\text { Specifies drug class to be used as first-line treatment and longer-term } \\
\text { follow-up treatment options if BP remains uncontrolled }\end{array}$ \\
\hline AHA/ACC/CDC & Patients categorised based on stage of hypertension & Suggests drug classes to be used, monitoring and follow-up options \\
\hline CHEP & Provides algorithms for diagnosis and treatment & $\begin{array}{l}\text { Specifies drug classes to be used as first-line treatment and longer-term } \\
\text { follow-up treatment options if BP remains uncontrolled }\end{array}$ \\
\hline $\mathrm{ESH} / \mathrm{ESC}$ & Patients categorised based on low or high risk & $\begin{array}{l}\text { Describes steps to be taken in moving to a more intensive therapy } \\
\text { through dose titration or adding more drugs } \\
\text { No recommendations on drug classes or doses }\end{array}$ \\
\hline France & No algorithm provided & $\mathrm{n} / \mathrm{a}$ \\
\hline NICE & $\begin{array}{l}\text { Diagnosis and treatment algorithms. Treatment } \\
\text { algorithm categorised based on age and race }\end{array}$ & $\begin{array}{l}\text { Recommends drug classes to be used for initial therapy and drug } \\
\text { combinations to be considered if BP remains uncontrolled }\end{array}$ \\
\hline Taiwan & $\begin{array}{l}\text { Patients categorised based on BP and non-high risk } \\
\text { or high risk }\end{array}$ & $\begin{array}{l}\text { Specifies the number of drugs to be prescribed but not specific drug } \\
\text { classes or doses }\end{array}$ \\
\hline China & $\begin{array}{l}\text { Patients categorised based on BP and risk } \\
\text { assessment }\end{array}$ & $\begin{array}{l}\text { Specifies drug classes to be used as first-line treatment and longer-term } \\
\text { follow-up treatment options if BP remains uncontrolled }\end{array}$ \\
\hline
\end{tabular}

AHA/ACC/CDC American Hypertension Association/American College of Cardiology/Centers for Disease Control and Prevention, ASH/ISH American Society of Hypertension/International Society of Hypertension, CHEP Canadian hypertension education program, ESH/ESC European Society of Hypertension/European Society of Cardiology, JNC 8 Eighth Joint National Committee, NICE National Institute for Clinical Excellence (UK), $B P$ blood pressure, $C K D$ chronic kidney disease, $n / a$ not applicable

\subsection{Treatment Algorithms}

With the exception of the French guidelines, which chose to focus on a target timeframe for BP control and a specific triple therapy if needed, all the guidelines discussed include a treatment algorithm (summarised in Table 6 [311]). In the case of the AHA/ACC/CDC advisory, the treatment algorithm and its development are the principal outcomes of the advisory [4].

The treatment algorithms were designed to provide a simplified treatment guide to be used as a tool by clinicians to facilitate and aid standardisation of treatment. They are seen as an effective, concise method of communicating the guidelines to both healthcare practitioners and patients. All the algorithms provide guidance based on the patients initial BP except for JNC 8, which uses goal BP to categorise patients. Some algorithms further sub-divide patient groups based on other risk factors such as age, race and comorbidities.

There are several examples of other successful hypertension treatment algorithms. For example, the Simplified Treatment Intervention to Control Hypertension (STITCH) algorithm developed in Canada is thought to have resulted in a $12 \%$ absolute (20\% relative) improvement in the proportion of clinical practices reaching target BP compared with practices implementing the usual guideline care [35]. In addition, the Kaiser Permanente algorithm, a tool utilised in a wider system-level approach to manage hypertension, is thought to have played an important role in achieving the highest $\mathrm{BP}$ control rate $(85 \%)$ in the world [36].

\section{Treatment Regimens for the General Population}

The level of detail provided in the treatment regimens varies between the guidelines, with some specifying a precise order in which the drugs should be prescribed whereas others make more general recommendations (Table 7). With the exception of the French, NICE and JNC 8 guidelines, the other guidelines under review recommend commencing pharmacological treatment in patients with stage 1 hypertension with one antihypertensive therapy and stage 2 patients with two therapies [4-7, $10,11]$. The French and NICE guidelines both recommend commencing treatment of stage 2 patients with one antihypertensive therapy $[8,9]$. Whereas, the JNC 8 guidelines state that at the physician's discretion, the treatment of both stage 1 and 2 patients can be initiated with either one or two therapies, as there is not sufficient evidence to support a specific dosing strategy [3].

The JNC 8, ESH/ESC, CHEP, Taiwan and China guidelines do not advise on a definitive order in which the drug classes should be prescribed [3, 6, 7, 10, 11]. Although the NICE and AHA/ACC/CDC guidelines provide drug class-specific recommendations, there is no 
Table 7 Preferred treatment options for general population by guideline

\begin{tabular}{|c|c|c|c|}
\hline Guidelines & Initial treatment & Two-drug combinations & Three-drug combinations \\
\hline JNC 8 & $\begin{array}{l}\text { Thiazide diuretic, } \mathrm{CCB}, \mathrm{ACEI} \text { or ARB } \\
\text { Alone or in combination }\end{array}$ & $\begin{array}{l}\text { Add a drug from another class: thiazide } \\
\text { diuretic, CCB, ACEI or ARB }\end{array}$ & $\mathrm{CCB}+$ thiazide $+\mathrm{ACEI}$ or $\mathrm{ARB}$ \\
\hline ASH/ISH & $\begin{array}{l}\text { Stage 1: ACEI or ARB } \\
\text { Stage 2: } 2 \text { drugs }\end{array}$ & $\mathrm{CCB}$ or thiazide $+\mathrm{ACEI}$ or $\mathrm{ARB}$ & $\mathrm{CCB}+$ thiazide + ACEI or ARB \\
\hline $\begin{array}{l}\mathrm{AHA} / \\
\mathrm{ACC} / \\
\mathrm{CDC}\end{array}$ & $\begin{array}{l}\text { Stage 1: Thiazide for most patients or ACEI, } \\
\text { ARB, CCB } \\
\text { Stage 2: Thiazide + ACEI, ARB or CCB } \\
\text { OR ACEI + CCB }\end{array}$ & $\begin{array}{l}\text { Add a drug from another class, either, } \\
\text { thiazide diuretic, CCB, ACEI or ARB }\end{array}$ & Not specified \\
\hline CHEP & $\begin{array}{l}\text { Thiazide, } \beta \text {-blocker, ACEI, ARB, CCB } \\
\text { Consider combination if SBP } \geq 20 \mathrm{mmHg} \\
\text { or DBP } \geq 10 \mathrm{mmHg} \text { above target }\end{array}$ & $\begin{array}{l}\text { Add a drug from another class, either, } \\
\text { thiazide, } \beta \text {-blocker, CCB, ACEI or } \\
\text { ARB }\end{array}$ & Not specified \\
\hline ESH/ESC & $\begin{array}{l}\text { Stage 1: Diuretics, ACEI, ARB, CCB or } \beta \text { - } \\
\text { blocker } \\
\text { Stage 2: } 2 \text { drugs }\end{array}$ & $\begin{array}{l}\text { Preferred combinations: } \\
\text { Thiazide + ARB or ACEI } \\
\text { Thiazide + CCB } \\
\text { CCB + ARB or ACEI }\end{array}$ & $\begin{array}{l}\text { Add a drug from another class: thiazide } \\
\text { diuretic, CCB, ACEI, ARB or } \beta \text { - } \\
\text { blocker }\end{array}$ \\
\hline France & $\begin{array}{l}\text { Initiating treatment with ARB or ACEI } \\
\text { (better persistence versus diuretic or } \beta \text { - } \\
\text { blocker) } \\
\text { CCB (for adherence) is preferred versus } \\
\text { diuretic or } \beta \text {-blocker }\end{array}$ & $\begin{array}{l}\text { Add a drug from another class: thiazide, } \\
\beta \text {-blocker, CCB, ACEI or ARB. }\end{array}$ & $\mathrm{CCB}+$ thiazide $+\mathrm{ACEI}$ or $\mathrm{ARB}$ \\
\hline NICE & $\begin{array}{l}<55 \text { years, } \mathrm{ACEI} \text { or } \mathrm{ARB} \\
>55 \text { years } \mathrm{CCB}\end{array}$ & $\mathrm{CCB}+\mathrm{ACEI}$ or $\mathrm{ARB}$ & $\mathrm{CCB}+$ thiazide $+\mathrm{ACEI}$ or $\mathrm{ARB}$ \\
\hline Taiwan & $\begin{array}{l}\text { Stage 1: Thiazide diuretic, CCB, ARB or } \\
\text { ACEI } \\
\text { Stage 2: } 2 \text { drugs }\end{array}$ & ACEI or ARB + CCB or thiazide & $\mathrm{CCB}+$ thiazide $+\mathrm{ACEI}$ or $\mathrm{ARB}$ \\
\hline China & $\begin{array}{l}\text { Stage 1: Thiazide diuretic, CCB, ARB, } \\
\text { ACEI or } \beta \text {-blocker } \\
\text { Stage 2: SPCs of } 2 \text { drugs }\end{array}$ & $\begin{array}{l}\mathrm{CCB}+\mathrm{ACEI} \text { or ARB } \\
\text { OR ACEI or ARB }+ \text { thiazide } \\
\text { OR CCB }+ \text { thiazide. } \\
\text { OR CCB }+\beta \text {-blocker }\end{array}$ & $\begin{array}{l}\mathrm{CCB}+\mathrm{ACEI} \text { or } \mathrm{ARB}+\text { thiazide } \\
\text { OR CCB }+\mathrm{ACEI} \text { or } \mathrm{ARB}+\beta \text {-blocker } \\
\text { OR ACEI or ARB }+ \text { thiazide }+ \\
\alpha \text { - blocker }\end{array}$ \\
\hline
\end{tabular}

AHA/ACC/CDC American Hypertension Association/American College of Cardiology/Centers for Disease Control and Prevention, ASH/ISH American Society of Hypertension/International Society of Hypertension, CHEP Canadian hypertension education program, ESH/ESC European Society of Hypertension/European Society of Cardiology, JNC 8 Eighth Joint National Committee, NICE National Institute for Clinical Excellence (UK), $A C E I$ angiotensin converting enzyme inhibitor, $A R B$ angiotensin receptor blocker, $C C B$ calcium channel blocker, $S P C$ single pill combination

consensus on which class of drug is best for initiating therapy; AHA/ACC/CDC recommends a thiazide diuretic [4], whereas the French guidelines recommend an ACEI or ARB (due to improved persistence) [9]. The NICE guidelines suggests a CCB (for patients $>55$ years of age or black) or an ACEI or ARB (for patients aged $<55$ years) [8]. In this respect, the ASH/ISH guidelines are very similar to NICE and recommend the use of a CCB or thiazide for patients aged $\geq 60$ years or black, and an ACEI or ARB for those aged $<60$ years [5]. The lack of a consensus on the antihypertensive drug class for initiating treatment reflects the absence of conclusive clinical evidence to demonstrate that a specific drug class is superior [3,7].

As there are no RCTs to support an optimal dosing strategy, with the exception of the ASH/ISH and JNC 8 guidelines there are no recommended dosing strategies provided by the guidelines under review [3-11]. The ASH/ISH guidelines suggest that the initial dose of a drug should be at least half of the maximum recommended dose, so that only one up-titration is required to reach the maximum recommended level [5]. JNC 8 guidelines provide three suggested dosing strategies: (1) start one drug, titrate to maximum dose then add a second drug; (2) start one drug, then add a second drug before achieving maximal dose of the first drug; or (3) begin with two drugs at the same time, either as two separate pills or as a single pill combination. Nevertheless, JNC 8 panel members emphasise such dosing strategies are discretionary, and that the final decision should be left to the clinician and patient [3]. 
Another factor considered by some of the guidelines is suggested timeframes for adjusting treatments (either altering the dose or adding additional drugs) until $\mathrm{BP}$ is controlled. The JNC 8, ASH/ISH, AHA/ACC/CDC, ESH/ ESC and CHEP guidelines recommend dose and antihypertensive treatments should be reviewed and modified every 2-4 weeks until an appropriate regimen is established [3-7]. The French guidelines suggest a similar timeframe, with review consultations provided once a month [9].

Although all the guidelines acknowledge that the majority of patients will require multiple drugs to gain BP control, there is no overall consensus regarding which drug combinations are most effective. This is due to the lack of clinical evidence available, as although trials have shown that combining drugs from two classes improves BP control [37] and patient adherence [7, 38], there are few trials which have compared the effectiveness of different drug combinations [7]. A summary of the preferred drug combinations is presented in Table 7. An interesting observation is that there seems to be a consensus forming between the guidelines, where the supporting evidence and clinical experience has led to the majority of guidelines preferring an ACEI or ARB combined with a CCB, or indeed a thiazide diuretic $[3,5,7$, $8,10]$. The only drug combination that is advised against by all guidelines is combining ACEI and ARB, due to the increased risk of end-stage renal disease and stroke identified by the ONTARGET (an ARB in combination with an ACEI) [39] and ALTITUDE (direct renin inhibitor, aliskiren, in combination with ACEI or ARB) studies, which investigated the effect of dual renin-angiotensin-aldosterone system (RAAS) blockade in patients already undergoing treatment for hypertension [40]. In addition, the ESH/ESC, ASH/ISH, French and Taiwan guidelines also recommend caution when prescribing thiazides with $\beta$-blockers as this combination has been associated with an increased risk of developing diabetes $[5,7,9,10]$.

When three drugs are required to achieve BP control, the French, NICE, JNC 8, Taiwan and ASH/ISH guidelines all recommend combining $\mathrm{ACEI} / \mathrm{ARB}$ with a $\mathrm{CCB}$ and a diuretic [8, 9]. The China guidelines agree with this but also suggest additional possible combinations such as an $\alpha$ blocker in combination with an ACEI/ARB and a diuretic [11]. The NICE guidelines suggest that $\alpha$-blockers should be considered for use in triple therapy if other classes are not effective or not tolerated [8]. The ESH/ESC, ASH/ISH and CHEP guidelines do not specify a preferred triple drug combination [5-7].

\subsection{Use of Single Pill Combinations (SPC)}

SPCs are recognised as having an important role in the control of $\mathrm{BP}$ as they reduce the number of pills to be taken, thereby simplifying the treatment regimen, and improving patient adherence [41]. Analysis of RCTs has shown that early use of SPCs (including as first-line therapy) may enhance BP control [42]. With the exception of NICE and AHA/ACC/CDC guidelines-where SPCs are not mentioned-all guidelines discussed, and both the STITCH and Kaiser Permanente algorithms, recommend using SPCs to some extent [3, 5-7, 9-11, 35, 36]. However, there are some differences in the setting in which they are mentioned; for example, China and Taiwan guidelines specifically recommend that SPCs are used for initial treatment should more than one drug be required [10, 11], whereas the French guidelines recommend their use if BP is not controlled within one month of commencing treatment [9]. Moreover, the ASH/ISH guidelines state that SPCs can be used to simplify treatment but with the proviso that they may be more expensive than other agents [5]. This is in contrast to the Taiwan guidelines which state that SPCs are always cheaper than the individual component drugs [10]; a claim which is supported by studies that have analysed the cost effectiveness of SPCs in the USA [43, 44]. These studies have shown that drug, ambulatory, and hospital costs are all significantly lower for patients prescribed SPCs compared with loose dose combinations [43, 44]. With an increasing range of both two and three drug SPCs becoming available, the increasing flexibility of this form of treatment is likely to facilitate their further use [7], although issues regarding their cost and lack of data from clinical trials still remain to be overcome.

\section{Treatment Recommendations for Specific Patient Groups}

All guidelines recognise that specific treatment advice is required for selected populations with different requirements to the general population due to age, ethnicity and comorbidities; Table 8 summarises these recommendations [3-11].

The ASH/ISH, ESH/ESC, JNC 8, NICE and CHEP guidelines all recommend initiating treatment of black patients with either a CCB or thiazide diuretic as there is evidence [principally from the Antihypertensive and LipidLowering Treatment to Prevent Heart Attack (ALLHAT) study] that ACEI are less effective for this group [3, 5-8, 45, 46]. The China, Taiwan, AHA/ACC/CDC and French guidelines did not provide any specific advice for black patients [9-11, 36].

Although there are no RCTs investigating the treatment of hypertension during pregnancy, the ESH/ESC, NICE (provided in a separate set of guidelines entitled 'Hypertension in Pregnancy' [47]) ASH/ISH, China and Taiwan guidelines provide specific recommendations for this group 
Table 8 Recommended therapies specified by each guideline for specific populations [3-11]

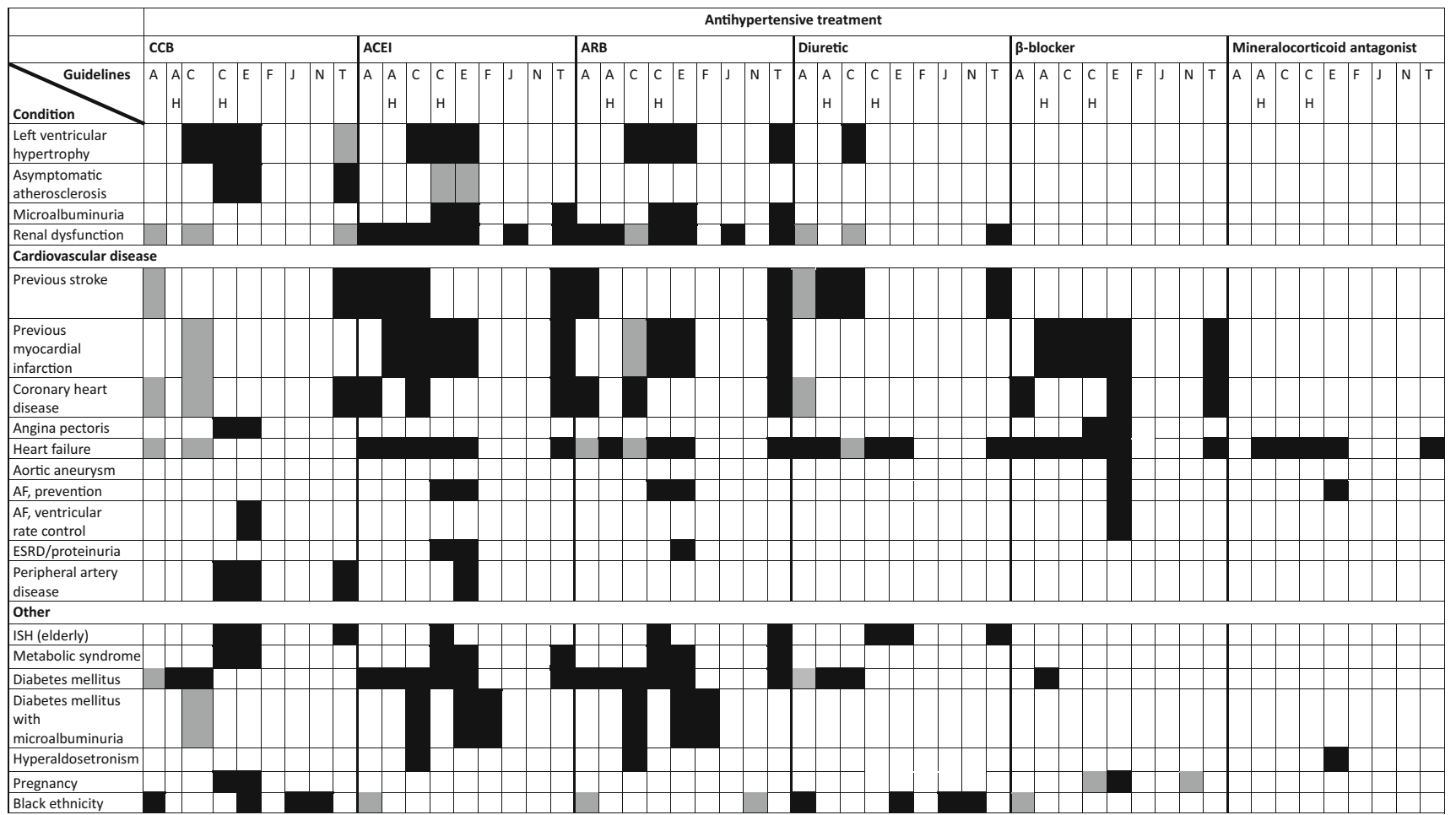

Black squares refer to initial therapy recommendations; grey squares refer to 2nd line therapy recommendations

$C$ CHEP, $T$ Taiwan, A ASH/ISH, $E$ ESH/ESC, $J$ JNC8, $N$ NICE, $C H$ China, AH AHA/ACC/CDC, $F$ France, AHA/ACC/CDC American Hypertension Association/American College of Cardiology/Centers for Disease Control and Prevention, ASH/ISH American Society of Hypertension/International Society of Hypertension, CHEP Canadian hypertension education program, ESH/ESC European Society of Hypertension/ European Society of Cardiology, JNC 8 Eighth Joint National Committee, NICE National Institute for Clinical Excellence (UK), ACEI angiotensin converting enzyme inhibitor, $A F$ atrial fibrillation, $A R B$ angiotensin receptor blocker, $C C B$ calcium channel blocker, ESRD end-stage renal disease, $I S H$ isolated systolic hypertension

based on expert opinion $[5,7,8,10,11]$. In addition to the recommended use of CCBs (specifically, nifedipine in the ESH/ESC and NICE guidelines [7, 47]) and $\beta$-blockers (specifically, labetatol, as atenolol has been associated with foetal growth retardation [7, 10, 47]; Table 8), the $\alpha$-2adrenergic agonist, $\alpha$-methyldopa, is recommended by the ASH/ISH, ESH/ESC, NICE, Taiwan and Chinese guidelines $[5,7,10,11,47]$ and hydralazine is recommended by the NICE guidelines [47]. The Taiwan, NICE and ESH/ ESC guidelines state that ACEI and ARBs should not be used because of their teratogenicity and diuretics should be avoided in women with reduced plasma volume $[7,8,10$, 47].

The NICE and ASH/ISH guidelines are the only guidelines with specific drug recommendations for older patients (those $>55$ years in NICE and $\geq 60$ years ASH/ ISH). Both these guidelines recommend commencing treatment with a CCB or thiazide diuretic in the older population as opposed to an ACEI or ARB in the younger population $[5,8]$.
All the guidelines emphasise the importance of taking into consideration other comorbidities when determining the optimal form of treatment. For example, JNC 8 guidelines stipulate that for patients with CKD (regardless of race or diabetes status), the initial or add-on antihypertensive treatment should include an ACEI or ARB to improve kidney outcomes (4). This recommendation is also supported by the Taiwan, CHEP, ASH/ISH, ESH/ESC, China and JNC 8 guidelines [3, 5-7, 10, 11].

In patients with a history of myocardial infarction, heart failure or angina pectoris, $\beta$-blocker use has been found to be highly effective in preventing CV events [48]. To reflect this (although not recommended by many of the guidelines for the treatment of the general population) $\beta$-blockers are specifically recommended for use in these patient groups by the ESH/ESC, Taiwan, China, ASH/ISH, AHA/ACC/ CDC, CHEP and NICE guidelines [4-8, 10, 11].

The ESH/ESC, Taiwan, NICE and ASH/ISH guidelines each provide guidance for patients with resistant hypertension $[5,7,8,10]$. In addition to advising on the need to 
identify the underlying cause of resistant hypertension (e.g. sleep apnoea, improper BP monitoring, poor patient adherence, additional pharmacological treatments which may exacerbate hypertension or reduce the effectiveness of anti-hypertensive drugs), the guidelines recommend health care practitioners to support the patient in implementing lifestyle modifications, adjust their current antihypertensive medications as appropriate, and add a mineralocorticoid antagonist, such as spironolactone to the prescribed medications $[5,7,8,10]$. As an alternative form of treatment, renal denervation is briefly discussed in the ESH/ESC guidelines [7]. Both the ESH/ESC guidelines and a position paper published by the ESH conclude that at present there is insufficient understanding of what factors determine whether the procedure is likely to be successful and they state that there is insufficient safety and efficacy evidence from RCTs to form any recommendations [7, 49]. This has been highlighted by the recent publication of Simplicity HTN-3, which in contrast to previous studies [27, 49, 50] has found that renal denervation does not reduce BP in patients with resistant hypertension [50]. As such, much more research is required to fully understand the role of this controversial form of treatment.

\section{Conclusions}

Treatment guidelines provide an essential bridge in communicating up-to-date information from clinical trials to clinicians, so that they in turn can provide the best form of treatment for patients. Despite being produced by a number of different organisations from around the world, the guidelines presented in this review [3-11] share many common recommendations in alignment with the existing evidence base within this large therapy area. The revised guidelines recently released by the Japanese Society of Hypertension (JSH) are also generally in alignment with those discussed in detail in this review [51]. However, one of the principal differences is that the JSH recommend relatively aggressive treatment of elderly hypertensive patients, due to the particularly high incidence of stroke in the Japanese population. Indeed, the guidelines recommend a threshold of $\geq 140 / 90 \mathrm{mmHg}$ for initiating treatment of the elderly and a BP target of $<150 / 90 \mathrm{mmHg}$ (or $<140$ / $90 \mathrm{mmHg}$ if tolerated) for patients $>75$ years old [51]. Across the guidelines, the BP target for the elderly is one of the main areas where no consensus has been reached and it is certainly an area that would benefit from further clinical evidence to establish the optimal targets for this group.

Where disparities in the recommendations do exist, it is generally due to a lack of consistent evidence from clinical trials. Some of the guidelines, such as the ESH/ESC and NICE guidelines highlight this problem and prompt for gaps in the data to be addressed by posing questions (e.g. 'Should elderly patients with a SBP between 140 and $160 \mathrm{mmHg}$ be given antihypertensive drug treatments?' [7]) which, should they be answered, would in turn strengthen future recommendations [7, 8]. We have already discussed gaps in data concerning age, however, racial differences, are also not adequately addressed in the current evidence base that shapes these guidelines. Indeed, current evidence largely examines hypertension management in Caucasian populations, which may not be transposable to Asian and black populations, for example. An exception to this is the recommendation to initiate treatment of black patients with either a CCB or thiazide diuretic, principally based on evidence from the ALLHAT subgroup analysis $[3,5-8,45,46]$. If greater consideration is placed on racial differences in future studies, differences in recommendations observed across national guidelines may widen. A separate limitation is that there is little consideration for the different structures in healthcare systems (e.g. accessibility, funding) during the development of guidelines that could limit their ease in adoption into clinical practice.

\subsection{Expert Opinion}

\subsubsection{Guideline Implementation and Impact}

Although guidelines themselves are useful tools, proactive steps and strategies for their successful implementation are essential to maximise their benefit. Although all the guidelines presented here were developed by independent associations, government endorsement, credible leadership from clinical practitioners and support from the pharmaceutical industry are required in their implementation. Once implemented it is also critical that their outcome and impact are monitored to help inform and leverage future changes.

Countries have different problems to overcome in implementing guidelines. For example, in France where BP control is no longer a major government priority, one of the major challenges is the lack of government backing and financial support. Whereas, in the UK, although the NICE guidelines were developed independently, they have gained government support and are aligned with the government performance managed health policy [quality outcomes framework (QOF)], a scheme to improve the quality of care through providing financial incentives to general practitioners. The QOF system both incentivises clinicians and has generated an electronic database that can be used to monitor BP control rates and measure the impact of new interventions. In England, BP control rates have steadily improved; in 2011, $66 \%$ of men and $61 \%$ of women receiving treatment for hypertension were classified as having controlled BP [52]. 
It is difficult to accurately assess the impact of implementing guidelines, however, there is some evidence that suggests guidelines are proving beneficial. For example, since the launch of CHEP in 1999, $66 \%$ of patients with hypertension now have controlled BP (compared with $13 \%$ before CHEP), physician visits have doubled, antihypertensive use has tripled, and the decline in hypertension-related CV complications has accelerated [53]. This is despite CHEP being a voluntary initiative that makes recommendations independent of government influence. Although this has advantages, such as not having to take into account economic factors, it does create difficulties in leveraging the recommendations. One of the strategies taken to overcome this is the development of an interactive website to widely disseminate the recommendations.

In the USA, one of the factors contributing to poor BP control is thought to be the fragmented healthcare system and a lack of standardised guidelines and national implementation strategies. The creation of a national consensus guideline that combines both hypertension and other CVD guidelines to create an integrated strategy may be advantageous [54]. Once guidelines have been agreed upon it will be necessary to translate these into a specific set of performance measures, to incentivise their use, and monitor the progress made towards targets [54]. The success of the Kaiser Permanente initiative in California is thought to be due to several key elements including: a comprehensive hypertension registry, development and sharing of performance metrics, evidence-based guidelines, medical assistant visits for BP measurement and SPC pharmacotherapy [36]. Implementing a similar health system approach on a nationwide scale could be beneficial.

\subsubsection{Future Development of Guidelines}

To maintain their value and credibility and prevent inertia, it is essential that guidelines are steadily evolved to keep up to date with advancements in the subject. Guidelines should principally be developed by healthcare experts in the field, however, the involvement of patients in the process may add value (as exemplified by the NICE guidelines).

Guidelines are required to be evidence based and identify best practises through impartial evaluation of the available data. The resulting guidelines should be simple to follow and straightforward to implement. They must provide flexible recommendations, which consider the country's unique healthcare system, to both enable their implementation across a wide range of clinical practices and to facilitate patient specific personalisation of treatment.

A key message when considering guidelines for hypertension management is that they demonstrate evidencebased evolution, not revolution. Indeed, we need to consider that guidelines or recommendations need evolving steadily in order to gain confidence in the changes taking place.

Acknowledgments This review was funded by Bayer HealthCare. Medical writing and editorial assistance were provided by Katie White and Victoria Panagakis at Fishawack Communications Ltd.

Conflict of interest Prof. Kjeldsen has received lecture honoraria from AstraZeneca, Bayer, Medtronic, MSD, Takeda, honoraria for consulting from Bayer, Medtronic, Serodus, Takeda, and unrestricted grants from AstraZeneca, Hemo Sapiens and Pronova. Dr Feldman has received research support from Servier Canada, serves as a consultant/advisory board member for Actavis, Medtronic. Novartis and Servier and has received CME support from Forest. Prof. Chiang has been on the speaker's bureau for AstraZeneca, Bayer, Boehringer Ingelheim, Chugai, Daiichi-Sankyo, GSK, MSD, Novartis, Pfizer, Roche, Sanofi-Aventis, Servier, Tanabe, Takeda and TTY. Prof. Mourad has no conflict of interest for this topic. Prof. Zhang has no conflict of interest. Prof. Liu Lisheng has no conflict of interest. Prof. Wei Li has no conflict of interest. Prof. Bryan Williams has received research support from Novartis and honoraria for lectures from Novartis, Boehringer Ingelheim and Servier.

Open Access This article is distributed under the terms of the Creative Commons Attribution Noncommercial License which permits any noncommercial use, distribution, and reproduction in any medium, provided the original author(s) and the source are credited.

\section{References}

1. World Health Organisation. A global brief on hypertension: silent killer, global public health crisis. 2013. http://apps.who.int/iris/ bitstream/10665/79059/1/WHO_DCO_WHD_2013.2_eng.pdf?ua= 1. Accessed 19 June 2014.

2. He FJ, MacGregor GA. Cost of poor blood pressure control in the UK: 62000 unnecessary deaths per year. J Hum Hypertens. 2003; 17:455-7.

3. James PA, Oparil S, Carter BL, et al. 2014 evidence-based guideline for the management of high blood pressure in adults: report from the panel members appointed to the eighth joint national committee (JNC 8). JAMA. 2014;311:507-20.

4. Go AS, Bauman M, King SMC, et al. An effective approach to high blood pressure control: a science advisory from the American Heart Association, the American College of Cardiology, and the Centers for Disease Control and Prevention. Hypertension. 2014;63:878-85.

5. Weber MA, Schiffrin EL, White WB, et al. Clinical practice guidelines for the management of hypertension in the community a statement by the American Society of Hypertension and the International Society of Hypertension. J Hypertens. 2014;32:3-15.

6. Dasgupta K, Quinn RR, Zarnke KB, et al. The 2014 Canadian Hypertension Education Program (CHEP) recommendations for blood pressure measurement, diagnosis, assessment of risk, prevention and treatment of hypertension. Can $\mathrm{J}$ Cardiol. 2014;30:485-501.

7. Mancia G, Fagard R, Narkiewicz K, et al. 2013 ESH/ESC guidelines for the management of arterial hypertension: The Task Force for the management of arterial hypertension of the European Society of Hypertension (ESH) and of the European Society of Cardiology (ESC). Eur Heart J. 2013;34:2159-219. 
8. National Institute for Health and Care Excellence. Hypertension: clinical management of primary hypertension in adults (Clinical guideline 127). http://guidance.nice.org.uk/CG127. Accessed 19 June 2014.

9. Blacher J, Halimi JM, Hanon O, et al. Management of hypertension in adults: the 2013 French Society of Hypertension guidelines. Fundam Clin Pharmacol. 2014;28:1-9.

10. Chiang C-E, Wang T-D, Li Y-H, et al. 2010 Guidelines of the Taiwan Society of Cardiology for the management of hypertension. J Formos Med Assoc. 2010;109:740-73.

11. Liu LS. 2010 Chinese guidelines for the management of hypertension. Zhonghua Xin Xue Guan Bing Za Zhi. 2011;39:579-615.

12. Lovibond $\mathrm{K}$, Jowett $\mathrm{S}$, Barton $\mathrm{P}$, et al. Cost-effectiveness of options for the diagnosis of high blood pressure in primary care: a modelling study. Lancet. 2011;378:1219-30.

13. Beckett NS, Peters R, Fletcher AE, et al. Treatment of hypertension in patients 80 years of age or older. $\mathrm{N}$ Engl $\mathrm{J}$ Med. 2008;358:1887-98.

14. Wright JT Jr, Fine LJ, Lackland DT, et al. Evidence supporting a systolic blood pressure goal of less than $150 \mathrm{mmHg}$ in patients aged 60 years or older: the minority view. Ann Intern Med. 2014;160:499-503.

15. Mancia G, De Backer G, Dominiczak A, et al. 2007 Guidelines for the management of arterial hypertension: The Task Force for the Management of Arterial Hypertension of the European Society of Hypertension (ESH) and of the European Society of Cardiology (ESC). Eur Heart J. 2007;28:1462-536.

16. Chobanian AV, Bakris GL, Black HR, et al. Seventh report of the Joint National Committee on prevention, detection, evaluation, and treatment of high blood pressure. Hypertension. 2003;42:1206-52.

17. ACCORD Study Group. Effects of intensive blood-pressure control in type 2 diabetes mellitus. N Engl J Med. 2010;362:1575-85.

18. Hansson L, Zanchetti A, Carruthers SG, et al. Effects of intensive blood-pressure lowering and low-dose aspirin in patients with hypertension: principal results of the hypertension optimal treatment (HOT) randomised trial. Lancet. 1998;351:1755-62.

19. UK Prospective Diabetes Study Group. Tight blood pressure control and risk of macrovascular and microvascular complications in type 2 diabetes: UKPDS 38. BMJ. 1998;317:703-13.

20. Bangalore S, Kumar S, Lobach I, et al. Blood pressure targets in subjects with type 2 diabetes mellitus/impaired fasting glucose: observations from traditional and Bayesian random-effects metaanalyses of randomized trials. Circulation. 2011;123:2799-810.

21. Cooper-DeHoff RM, Gong Y, Handberg EM, et al. TIght blood pressure control and cardiovascular outcomes among hypertensive patients with diabetes and coronary artery disease. JAMA. 2010;304:61-8.

22. Reboldi G, Gentile G, Angeli F, et al. Effects of intensive blood pressure reduction on myocardial infarction and stroke in diabetes: a meta-analysis in 73,913 patients. J Hypertens. 2011;29:1253-69.

23. Arguedas JA, Perez MI, Wright JM. Treatment blood pressure targets for hypertension. Cochrane Database Syst Rev. 2009:CD004349.

24. Upadhyay A, Earley A, Haynes SM, et al. Systematic review: blood pressure target in chronic kidney disease and proteinuria as an effect modifier. Ann Intern Med. 2011;154:541-8.

25. Appel LJ, Wright JT, Greene T, et al. Intensive blood-pressure control in hypertensive chronic kidney disease. N Engl J Med. 2010;363:918-29.

26. Eckel RH, Jakicic JM, Ard JD, et al. AHA/ACC guideline on lifestyle management to reduce cardiovascular risk: A report of the American College of Cardiology/American Heart Association Task Force on practice guidelines. Circulation. 2014;129:25(Suppl. 2):S76-99.

27. Simplicity HTN-1 Investigators. Catheter-based renal sympathetic denervation for resistant hypertension: durability of blood pressure reduction out to 24 months. Hypertension. 2011;57:911-7.

28. Institute of Medicine. Sodium intake in populations. Assessment of evidence. 2013. http://www.iom.edu/Reports/2013/SodiumIntake-in-Populations-Assessment-of-Evidence.aspx. Accessed 5 Sept 2014.

29. Graudal N, Jürgens G, Baslund B, et al. Compared with usual sodium intake, low- and excessive-sodium diets are associated with increased mortality: a meta-analysis. Am J Hypertens. 2014;27:1129-37.

30. MRC Working Party. Medical Research Council trial of treatment of hypertension in older adults: principal results. BMJ. 1992;304:405-12.

31. Wiysonge CS, Bradley HA, Volmink J, et al. Beta-blockers for hypertension. Cochrane Database Syst Rev. 2012:CD002003.

32. Bakris GL, Fonseca V, Katholi RE, et al. Metabolic effects of carvedilol vs metoprolol in patients with type 2 diabetes mellitus and hypertension: a randomized controlled trial. JAMA. 2004;292:2227-36.

33. Manrique C, Giles TD, Ferdinand KC, et al. Realities of newer $\beta$ blockers for the management of hypertension. J Clin Hypertens. 2009;11:369-75.

34. Bonet S, Agustí A, Arnau JM, et al. B-adrenergic blocking agents in heart failure: benefits of vasodilating and nonvasodilating agents according to patients' characteristics: a meta-analysis of clinical trials. Arch Intern Med. 2000;160:621-7.

35. Feldman RD, Zou GY, Vandervoort MK, et al. A simplified approach to the treatment of uncomplicated hypertension: a cluster randomized, controlled trial. Hypertension. 2009;53:646-53.

36. Jaffe MG, Lee GA, Young JD, et al. Improved blood pressure control associated with a large-scale hypertension program. JAMA. 2013;310:699-705.

37. Wald DS, Law M, Morris JK, et al. Combination therapy versus monotherapy in reducing blood pressure: meta-analysis on 11,000 participants from 42 trials. Am J Med. 2009;122:290-300.

38. Corrao G, Parodi A, Zambon A, et al. Reduced discontinuation of antihypertensive treatment by two-drug combination as first step. Evidence from daily life practice. J Hypertens. 2010;28:1587-90.

39. ONTARGET Investigators. Telmisartan, ramipril, or both in patients at high risk for vascular events. $\mathrm{N}$ Engl $\mathrm{J}$ Med. 2008;358:1547-59.

40. Parving H-H, Brenner BM, McMurray JJV, et al. Cardiorenal end points in a trial of aliskiren for type 2 diabetes. $\mathrm{N}$ Engl $\mathrm{J}$ Med. 2012;367:2204-13.

41. Gupta AK, Arshad S, Poulter NR. Compliance, safety, and effectiveness of fixed-dose combinations of antihypertensive agents: a meta-analysis. Hypertension. 2010;55:399-407.

42. Kjeldsen SE, Messerli FH, Chiang C-E, et al. Are fixed-dose combination antihypertensives suitable as first-line therapy? Curr Med Res Opin. 2012;28:1685-97.

43. Dickson M, Plauschinat CA. Racial differences in medication compliance and healthcare utilization among hypertensive medicaid recipients: fixed-dose vs free-combination treatment. Ethn Dis. 2008; 18:204-9.

44. Dickson M, Plauschinat CA. Compliance with antihypertensive therapy in the elderly: a comparison of fixed-dose combination amlodipine/benazepril versus component-based free-combination therapy. Am J Cardiovasc Drugs. 2008;8:45-50.

45. The ALLHAT Officers. Coordinators for the ALLHAT Collaborative Research Group. Major outcomes in high-risk hypertensive patients randomized to angiotensin-converting enzyme inhibitor or calcium channel blocker vs diuretic: the antihypertensive and lipid-lowering treatment to prevent heart attack trial (ALLHAT). JAMA. 2002;288:2981-97.

46. Leenen FHH, Nwachuku CE, Black HR, et al. Clinical events in high-risk hypertensive patients randomly assigned to calcium 
channel blocker versus angiotensin-converting enzyme inhibitor in the antihypertensive and lipid-lowering treatment to prevent heart attack trial. Hypertension. 2006;48:374-84.

47. National Institute of Clinical Excellance. Hypertension in pregnancy, guideline 107. 2010. http://www.nice.org.uk/guidance/ CG107 Accessed 5 Sept 2014.

48. Law MR, Morris JK, Wald NJ. Use of blood pressure lowering drugs in the prevention of cardiovascular disease: meta-analysis of 147 randomised trials in the context of expectations from prospective epidemiological studies. BMJ. 2009;19:b1665.

49. Esler MD, Krum H, Schlaich M, et al. Renal sympathetic denervation for treatment of drug-resistant hypertension: oneyear results from the symplicity htn-2 randomized, controlled trial. Circulation. 2012;126:2976-82.

50. Symplicity HTN-2 Investigators, Esler MD, Krum H, et al. Renal sympathetic denervation in patients with treatment-resistant hypertension (The Symplicity HTN-2 Trial): a randomised controlled trial. Lancet. 2010;376:1903-9.

51. Shimamoto K, Ando K, Fukita T, et al. The Japanese society of hypertension guidelines for the management of hypertension (JSH 2014). Hypertens Res. 2014;37(4):253-387.

52. Knott C, Mindell J. Health Survey for England: 2011. 2011. http://www.hscic.gov.uk/catalogue/PUB09300/HSE2011-Ch3Hypertension.pdf. Accessed 19 June 2014.

53. McAlister FA, Feldman RD, Wyard K, et al. The impact of the Canadian hypertension education programme in its first decade. Eur Heart J. 2009;30:1434-9.

54. Peterson ED, Gaziano J, Greenland P. Recommendations for treating hypertension: what are the right goals and purposes? JAMA. 2013;311:474-6. 